\title{
Diurnal Variation of Simulated 2007 Summertime Precipitation over South Korea in a Real-Time Forecast Model System
}

\author{
Kyungna Kim ${ }^{1}$, Dae-Yong Eom ${ }^{1}$, Dong-Kyou Lee ${ }^{1}$ and Ying-Hwa Kuo ${ }^{2}$ \\ ${ }^{1}$ Atmospheric Sciences Program, School of Earth and Environmental Sciences, Seoul National University, Seoul, Korea \\ ${ }^{2}$ National Center for Atmospheric Research, Boulder, CO 80305, USA
}

(Manuscript received 26 June 2009; revised 6 August 2010; accepted 10 September 2010)

(C) The Korean Meteorological Society and Springer 2010

\begin{abstract}
A real-time forecast (RTF) system using Weather Research and Forecast (WRF) model version 2.2 is used to evaluate the diurnal variation of precipitation over South Korea in the summer (June to August) of 2007. The characteristics of the observed precipitation are also analyzed. The analysis and simulation period is divided into two sub-periods following the end of the changma, or East Asian monsoon, in 2007: Period_1 is from 1 June to 21 July, and Period 2 is from 22 July to 31 August.

A 24-h precipitation cycle is observed over the entire period. The diurnal variation of precipitation over the South Korea shows that the nighttime maximum precipitation in Period_1 is affected by a largescale system; in contrast, the daytime maximum precipitation in Period_2 resulted from mesoscale convections is induced by thermal instability and moisture advection. The phases of the diurnal variation of simulated precipitation are consistent with those of the observed precipitation. The daytime rainfall amount of simulated precipitation in Period_2 is overestimated, and the convective rain process significantly affects the simulated total precipitation. The daytime overestimated precipitation is associated with overestimations of low-level temperature and moisture during the daytime in the model simulations as compared with the observations.
\end{abstract}

Key words: Diurnal variation, real-time forecast, summertime precipitation, South Korea, Weather Research and Forecasting model

\section{Introduction}

Mesoscale numerical models have been widely used for shortterm forecasting of local precipitation and weather systems. During the last few decades, many attempts have been made to improve mesoscale models (Olson et al., 1995, Fritsch et al., 1998) by the enhancement of computing efficiency, the highresolution capability of models and the improved parameterization schemes of physical processes. In spite of these efforts, there still remain difficulties in accurate forecasting of determining the occurrence time and quantitative amount of precipitation. Recently, the reproducibility of diurnal variation in numerical models has been considered as one of the issues for improving predictions of the occurrence time, duration and amount of precipitation.

Corresponding Author: Prof. Dong-Kyou Lee, School of Earth and Environmental Sciences, Seoul National University, 599 Gwanak-ro, Gwanak-gu, Seoul 151-747, Korea.

E-mail:dklee@snu.ac.kr
The diurnal variation of precipitation has been investigated widely. Before weather satellites were in operation, studies were limited to land area (Bleeker and Andre, 1951; Wallace, 1975; Oki and Musiake, 1994; Zhou et al., 2008) since almost no observation on the ocean. Weather satellites made more studies over larger area, even in ocean area, with a coarse spatial resolution (Sorooshian et al., 2002; Yang and Smith, 2006; Liu and Zipser, 2008; Zhou et al., 2008). These data were also used to validate the diurnal variation of the model forecasts (Davis et al., 2003; Bechtold et al., 2004; Janowiak et al, 2007).

The diurnal variation of precipitation over South Korea has also been studied using observation data. Lim and Kwon (1998) used data from 31 observational stations from 1980 to 1996 and found that the diurnal variation of precipitation in the Korean peninsula exhibits some significant characteristics. The maximum precipitation is observed in the afternoon and early morning. In addition, Jung and Suh (2005) showed that the two maximum peaks of precipitation depend on the location; the afternoon maximum occurs over land, while the early morning maximum occurs over the west coastal region.

To evaluate the diurnal variation in model simulations, longterm averaged data is required. Since insufficient long-term model simulation data is available for the South Korean peninsula, this issue has not yet been studied. A real-time forecast (RTF) system using the Weather Research and Forecast (WRF) model has been in operation at the Seoul National University (SNU)-National Center for Atmospheric Research (NCAR) Joint Center for High-Impact Weather and Climate Research (JHWC) since November 2006. The objective of this study is to determine whether the RTF system can reproduce the diurnal variation of warm season precipitation. We focus on the period of 1 June to 31 August 2007. This period is the most annual rainfall season in Korea and is the first summer after RTF system has been operated. Before examining the model forecast data, the characteristics of the diurnal variation of observed precipitation are simply analyzed. The possible reasons of the errors in estimating the diurnal variation of precipitation using RTF are then investigated.

This paper is organized as follows. In Section 2, the data used in this study are explained and the model used in RTF system is described. Section 3 examines the characteristics of observed precipitation for the two periods in JJA 2007, which are formed 
by dividing the precipitation over the entire summer. The diurnal variation of precipitation simulated with the RTF model is examined in Section 4. The summary and conclusions are presented in Section 5.

\section{Model description and data}

The precipitation data used in this study are obtained from both observations and model forecasts. We executed this study for the period of June, July, and August 2007 over South Korea which is located between $35^{\circ} \mathrm{N}$ to $38^{\circ} \mathrm{N}$ latitude and $126^{\circ} \mathrm{E}$ to $129^{\circ} \mathrm{E}$ longitude. To represent the diurnal variation of precipitation, UTC is primarily used. The local standard time (LST) is $9 \mathrm{~h}$ ahead of UTC, and each time interval is analyzed from 0900 LST to the next 0900 LST. The simulated precipitation data is compared to the rain gauge data to examine the simulation capability of the diurnal variation of precipitation. In addition to precipitation, convective available potential energy (CAPE) from vertical sounding data at the Osan and Gwangju stations (Fig. 1b) is used to investigate thermal instability. The diurnal variation of precipitation properties is calculated from hourly accumulated rainfall data as a function of the time of day.

\section{a. Rain gauge data}

The observed precipitation is obtained from the 65 Korea Meteorological Administration (KMA) stations in South Korea, excluding island stations. Figure $1 \mathrm{~b}$ shows the spatial distribution of the 65 surface observational stations. In this study, hourly accumulated precipitation data are used to examine the characteristics of the diurnal variation. For comparison, the observed precipitation is converted to 3-hourly accumulated by averaging as like in the RTF simulation since the observed precipitation is hourly and the simulated is 3-hourly.

\section{b. Forecast model precipitation}

The model simulation data is taken from RTF system at JHWC. The numerical model for the RTF system is WRF model version 2.2 (Skamarock et al., 2005); it has a 27-km gridspacing configuration and 35 vertical levels for model domain (Fig. 1a). A brief description of the model configuration is included in Table 1. NCEP Global Forecast System (GFS) forecast data, which have a horizontal resolution of $1^{\circ}$ and 3-h time intervals, are used for the initial and boundary data. This model is integrated every day; it is initialized at 1200 UTC with interpolated GFS data. The forecasts extend to $72 \mathrm{~h}$, and the 12$\mathrm{h}$ forecast lead time is used. We analyze the model output data, which stored every $3 \mathrm{~h}$, from 0000 UTC (12-h forecast) to the next 0000 UTC (36-h forecast). For the comparison with the observed precipitation, simulated precipitation data are interpolated to the locations of 65 observational stations.

A modified version of the Kain-Fritsch cumulus parameterization scheme (Kain, 2004) is used for physics parameterization. The Betts-Miller-Janjic (Janjic, 1994, 2000) and GrellDevenyi Ensemble (Grell and Devenyi, 2002) are also used in the sensitivity experiment of the cumulus parameterization schemes.

\section{Results}

\section{a. Observed characteristics}

Before examining the real-time forecast data, the characteristics of the observed precipitation is analyzed. The temporal distribution of the daily mean precipitation is shown in Fig. 2a. To confirm the diurnal variation of precipitation, spectral analysis is performed using the data of hourly accumulated precipitation. Figure $2 \mathrm{~b}$ shows that the frequency of precipitation with a significance level over $99 \%$ is approximately

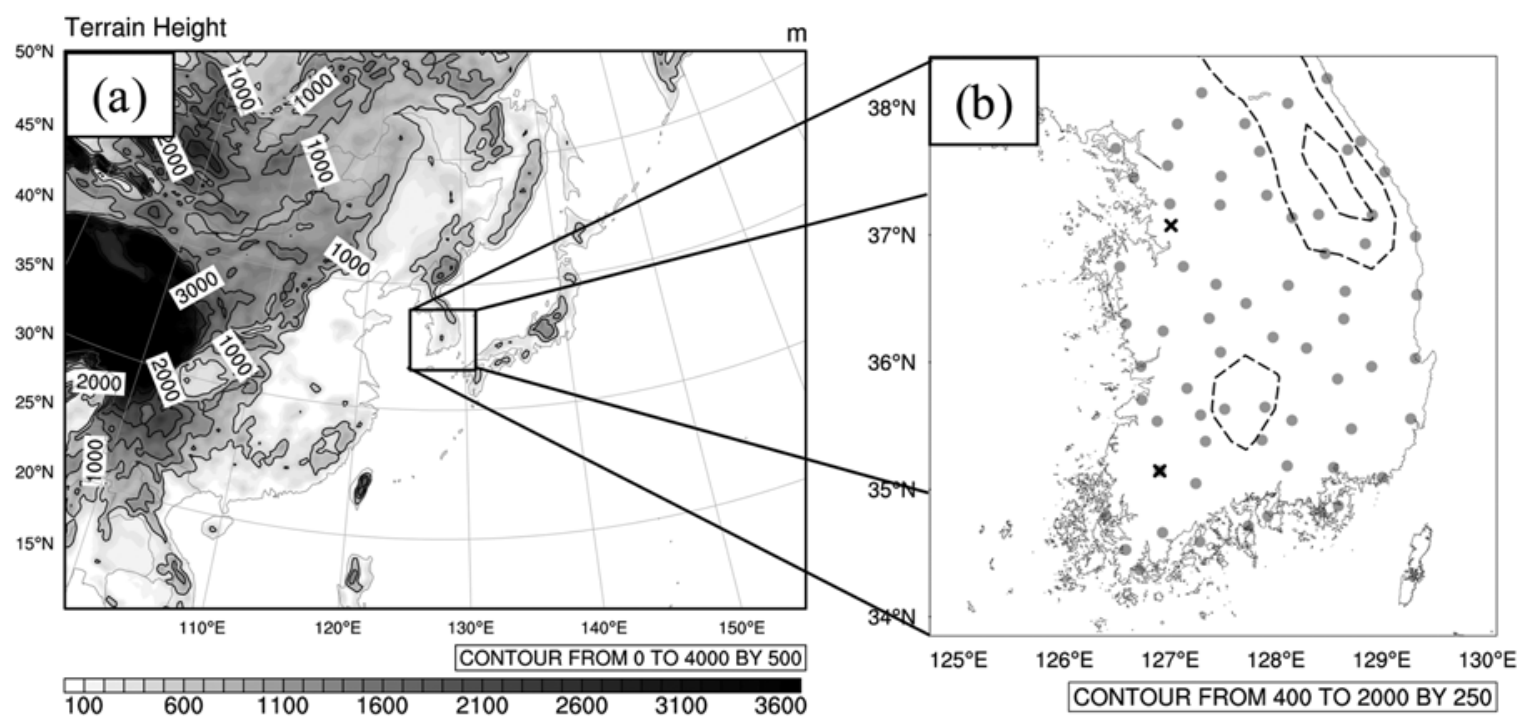

Fig. 1. Model domain and analysis area. (a) Model domain covers East-Asia region, which includes China, Korea, Japan, Taiwan, and some part of West Pacific Ocean. Shading and contour lines show terrain heights. Contour (shading) intervals are $500 \mathrm{~m}(100 \mathrm{~m})$. (b) On the analysis area of South Korea region, there are 65 stations of surface observations (gray dot) and vertical sounding observations (black cross), Osan and Gwangju. Dashed lines show terrain heights from $400 \mathrm{~m}$ to $2000 \mathrm{~m}$ by $250 \mathrm{~m}$. Contours near the coast line indicate the Taeback mountain range. 
Table 1. Configurations of realtime forecast system using WRF version 2.2.

\begin{tabular}{cc}
\hline Description & Domain 1 \\
\hline Horizontal grid size & $27 \mathrm{~km}$ \\
Horizontal grid \# & $238^{*} 180$ \\
Vertical Layers/Top & 35 sigma layers / 50hpa \\
Integrate time (int.) & $72 \mathrm{hr}(\Delta \mathrm{t}=120 \mathrm{~s})$ \\
Interval of producing output & $3 \mathrm{hr}$ \\
Explicit Moisture & WSM 6-class graupel scheme \\
& Kain-Fritsch (kain 2004), \\
CPS & Betts-Miller-Janjic (janjic 1994, 2000), \\
& Grell-Devenyi ensemble (Grell and \\
Deveny 2002) \\
Boundary Layer & YSU scheme \\
Long-wave radiation & rrtm radiation \\
Short-wave radiation & Dudhia scheme \\
Surface physics & Noah land-surface model \\
\hline
\end{tabular}

0.041 cycles per day, a 24-h period. This hourly accumulated precipitation data is examined for diurnal variations (Fig. 2c). The results appear to be consistent with those of the previous studies; the diurnal variation of the summer precipitation in
South Korea is characterized by two maximum peaks-one in the early morning and the other in the afternoon (Lim and Kwon, 1998; Jung and Suh, 2005).

In the Korean peninsula, warm season can be defined as Changma and after-Changma according to the precipitation characteristics. During the Changma period, the quasi-stationary front brings large amount of precipitation. After Changma period, northwest pacific high is enhanced and it becomes humid and hot environment. During this period, mesoscale convective system, typhoon, and thermal heating contributes to precipitation in this region. For these reasons, the analysis period in this study is divided into Period 1 and Period 2, beginning from the end date of the Changma in 2007 according to the KMA report: Period_1 is from 1 June to 21 July and Period_2 is from 22 July to 31 August (Fig. 3 ).

The relative vorticity and convective available potential energy (CAPE) are the most significant variables characterizing Period_2. Figure 3 shows a time series of the area-averaged relative vorticity at $500 \mathrm{hPa}, 6-\mathrm{h}$ accumulated precipitation, and station-averaged CAPE from Osan and Kwangju at 0000, 0600, 1200 , and 1800 UTC. The relative vorticity is computed using the global final (FNL) analysis dataset from the National Center for Environmental Prediction (NCEP). The time series of the area-averaged relative vorticity indicates that the mean relative vorticity during Period_1 is approximately $0.45 \times 10^{-5} \mathrm{~s}^{-1}$, indi-
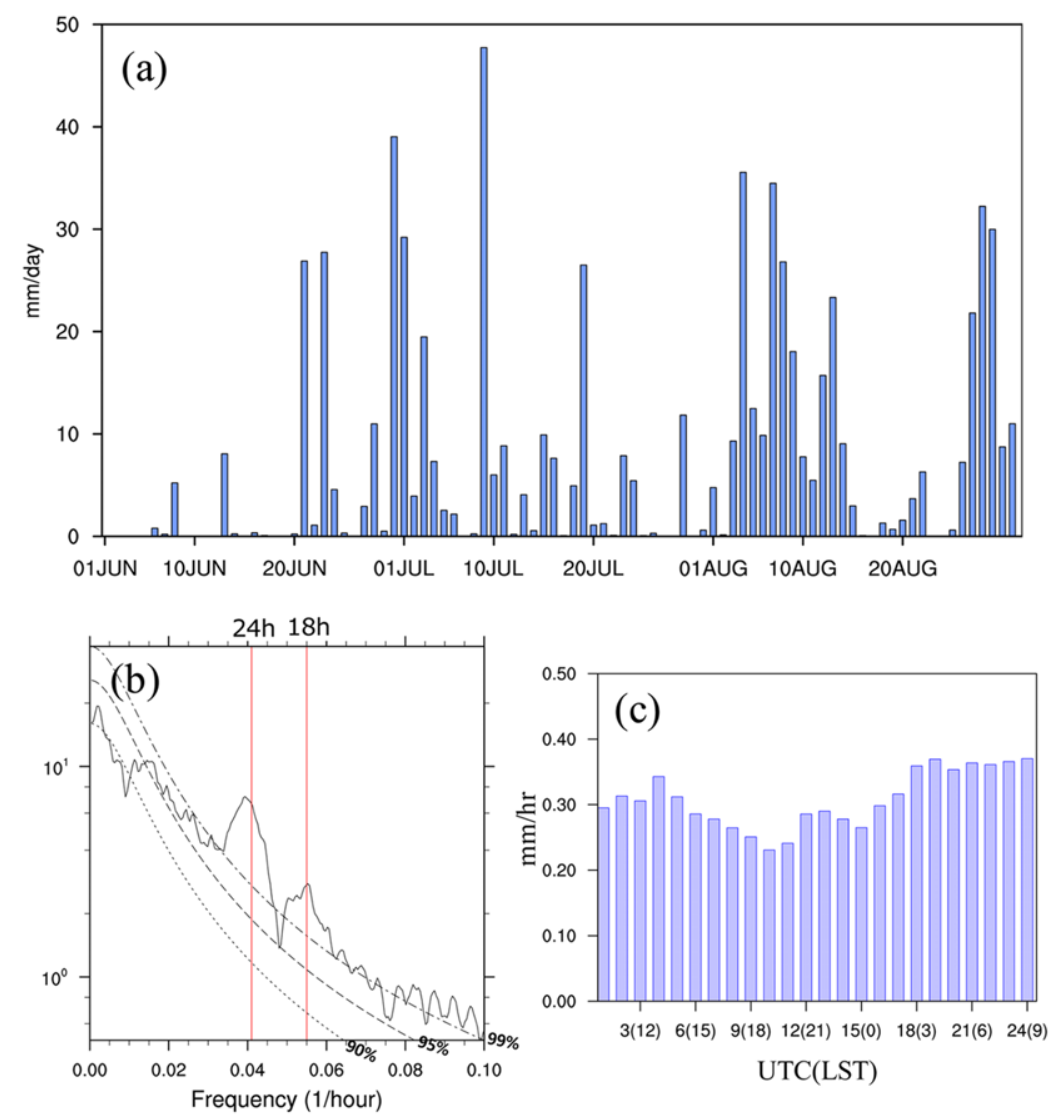

Fig. 2. Properties of observed precipitation of 65 stations during JJA 2007; (a) temporal distribution of daily mean precipitation; (b) a spectral analysis of hourly precipitation. Dash-dotted line is $99 \%$ significant level; and (c) diurnal variation of hourly precipitation. 


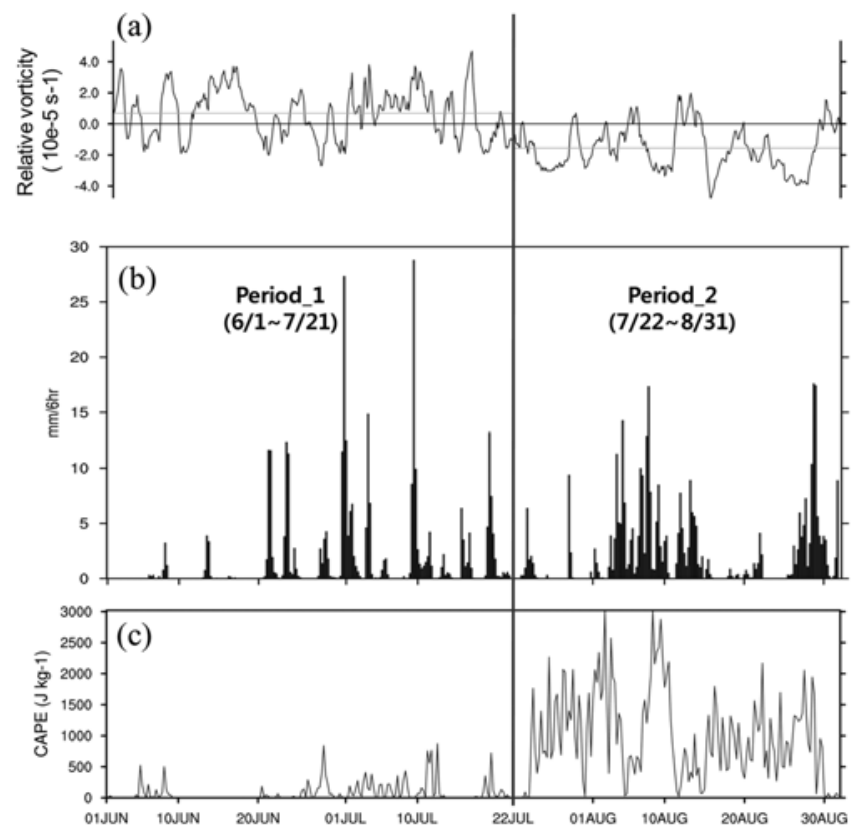

Fig. 3. Temporal distribution of (a) relative vorticity around South Korea, (b) 6-h accumulated and averaged precipitation from 65 observational stations, and (c) averaged convective available potential energy (CAPE) at Osan and Gwangju.

cating that cyclonic weather systems are dominant; in contrast, the mean relative vorticity during Period_2 is approximately $-1.68 \times$ $10^{-5} \mathrm{~s}^{-1}$ which indicates that anticyclonic weather systems prevailed. Figure $3 \mathrm{c}$ shows the time series of averaged CAPE at the Osan and Gwangju stations. Large CAPE values of up to $3000 \mathrm{~J} \mathrm{~kg}^{-1}$ develop continuously during Period_2 while CAPE exhibits low values of less than $500 \mathrm{~J} \mathrm{~kg}^{-1}$ during Period_1. The temporal distribution of relative vorticity and CAPE indicates that during Period_1, the synoptic-scale weather patterns are characterized and that mesoscale convective systems affect the precipitation during the Period_2. From the results, the different characteristics of the precipitation system are found to exist before and after the end of the changma.

The diurnal variation of the precipitation is analyzed for

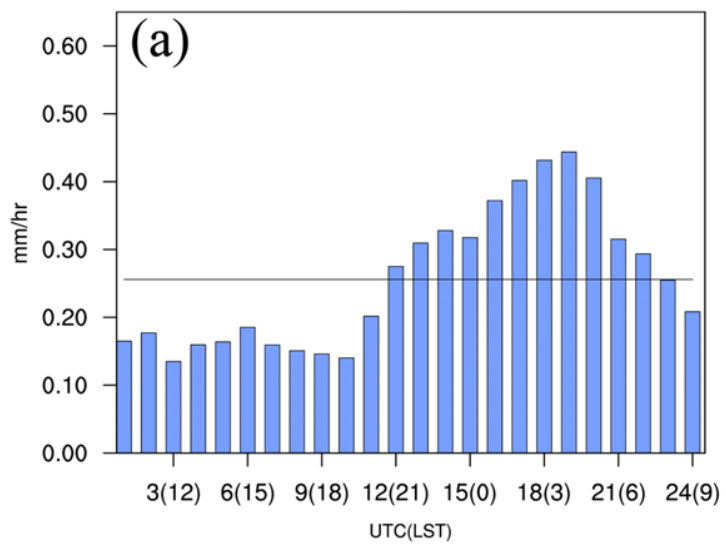

Period_1 and Period_2. Figure 4 shows that each period has not only different phases but also significant differences in amplitudes. Nighttime precipitation is more dominant during Period_1 while daytime precipitation prevails during Period_2. It can be inferred that different weather characteristics may result in the different diurnal variation. This is also consistent with that large-scale circulation may influence the physical processes of rainfall (Basu, 2007).

\section{b. Model results}

The temporal distribution of daily accumulated precipitation data from observation and the the model forecast over the South Korea for the entire study period is represented in Fig. 5. The vertical line in the middle of Fig. 5a separates Period_1 from Period_2 which is discussed in the previous section. The correlation between observed and simulated precipitation is calculated for each period: 0.95 for Period_1 and 0.89 for Period_2. The precipitation forecast agrees well with observed precipitation in terms of timing and quantity. However, in the spatial distribution of observed daily mean precipitation, there are large differences between Period_1 and Period 2; there is one local maximum in Period 1 while Period 2 has three. The local maxima of the simulated precipitation are not reproduced well. In Period_1, the simulated precipitation area appears to have shifted southward and thus it exhibits a maximum in the southeastern part of the Korean peninsula (Fig. 5d). In Period_2, the model reproduces the three local maxima in the observations except for the local maximum middle part of the area (Fig. 5e). Overall, the model forecast reproduces the daily variations of area-averaged precipitation over the Korean peninsula, but it does not perform well in reproducing the spatial distribution of time-averaged precipitation.

The diurnal variation of the simulated precipitation is presented for each period, together with the corresponding observed data, in Fig. 6. For both periods, the maximum convective rain for the simulated precipitation appears during the daytime, while the maximum non-convective rain occurs at night. In Period_2 (Fig. 6b), the maximum precipitation shows considerably larger amplitude than that observed. The precipitation

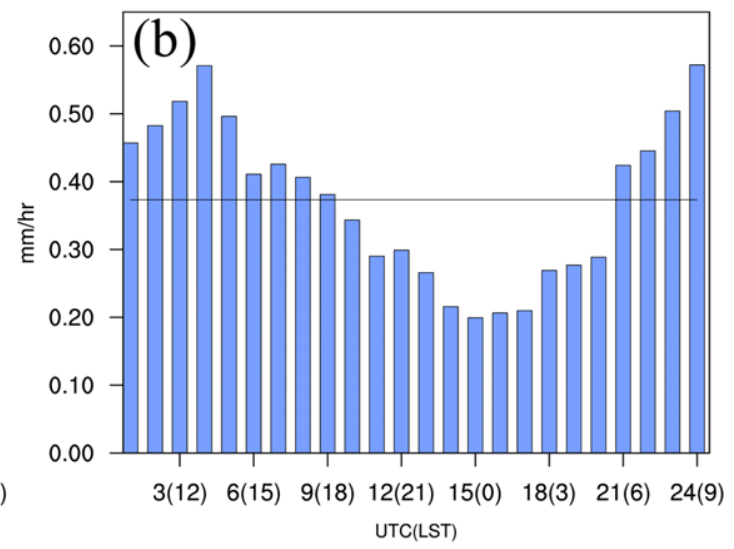

Fig. 4. Diurnal variation of precipitation during (a) Period_1, and (b) Period_2. Solid lines represent mean precipitation rate; $0.256 \mathrm{~mm} \mathrm{~h}^{-1}$ in Period_1, and $0.373 \mathrm{~mm} \mathrm{~h}^{-1}$ in Period_2. 

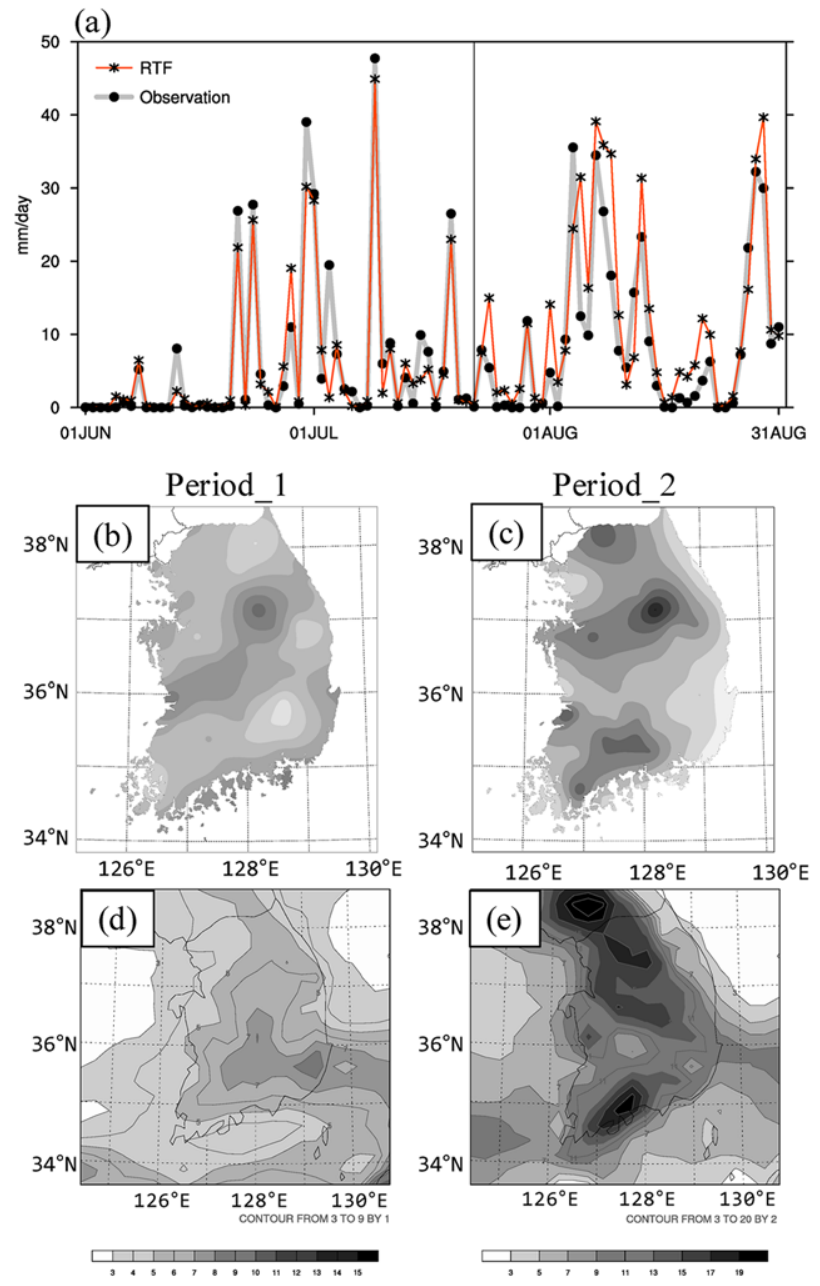

Fig. 5. Daily mean precipitation of (a) temporal distribution; (b-e) spatial distributions for both observation and RTF data. (a) The thick line with filled circles represents observations, and the thin line with asterisks indicates the RTF model. (b) and (c) indicate the observations; (d) and (e) indicate the RTF. The contour intervals are $1 \mathrm{~mm} \mathrm{~d}^{-1}$ for Period_1 in (b) and (d) and $2 \mathrm{~mm} \mathrm{~d}^{-1}$ for Period_2 in (c) and (e).

rate at the time of the maximum peak is almost $1 \mathrm{~mm}$ per $3 \mathrm{~h}$ higher than the observed peak, and the rate is slightly larger than that observed at other times. In previous studies (Yang and Slingo, 2001; Dai and Trenberth, 2004), simulated precipitation over land exhibited an unrealistically large diurnal range. The convective rain corresponds to the total precipitation tendency in Period 2. The simulated convective rain is dominant while the non-convective rain is slight in the night during Period_2.

As referred in the previous section, in Period 2 the occurrence of precipitation is influenced by thermal instability resulting from daytime heating, indicating that the precipitation peak in diurnal variation occurs in the afternoon. For large amounts of precipitation, sufficient moisture in the atmosphere is also one of the important factors To examine possible reasons for the over predicted daytime precipitation, the aver-
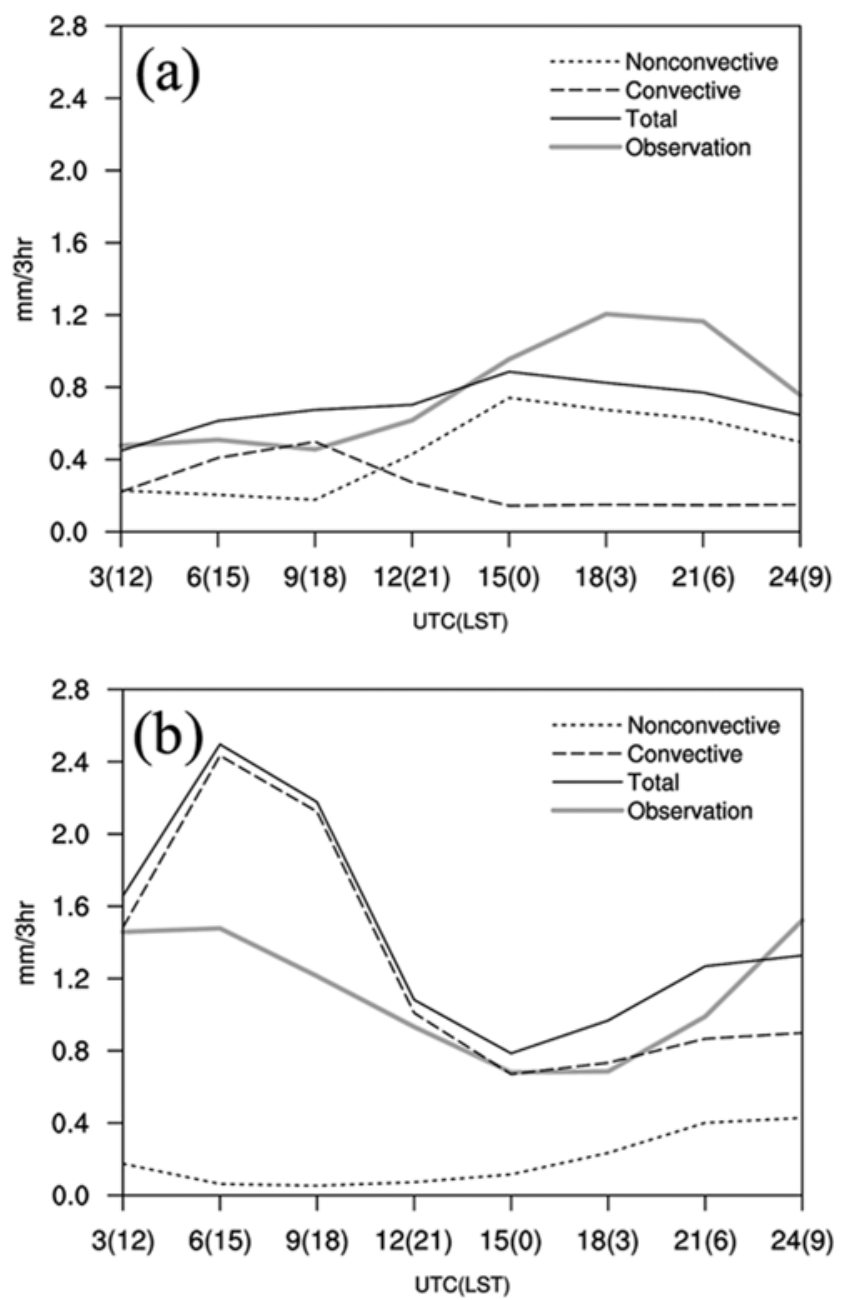

Fig. 6. Diurnal variation of precipitation for (a) Period 1 and (b) Period_2. The thick gray line depicts the observed precipitation, and the thin black line represents the simulated total precipitation. For the simulated precipitation, there are two types of precipitation: convective (dashed line) and non-convective (dotted line). Time is represented in UTC (LST) and the precipitation rate is in $\mathrm{mm}$ per $3 \mathrm{~h}$.

aged temperature and moisture over 41 days are analyzed for Period_2. Daily anomalies for the vertical structure of simulated temperature and mixing ratio-from FNL at 16 points over South Korea-are shown in Fig. 7. The diurnal variation of the temperature and mixing ratio is large at lower levels. For the observational data, the largest diurnal range in temperature $(2.6 \mathrm{~K})$ occurs at the lowest level, which is near the surface, while those above $850 \mathrm{hPa}$ are rarely affected by the diurnal cycle (Fig. 7a). The diurnal range of the simulated temperature at $975 \mathrm{hPa}$ is approximately $3.0 \mathrm{~K}$. In addition, at $0600 \mathrm{UTC}$, an anomaly of $975 \mathrm{hPa}$ shows a diurnal departure of $1.8 \mathrm{~K}$ from its daily mean (Fig. 7b). The daily anomalies of a vertical structure of simulated moisture from the FNL have a much larger diurnal range, especially at 0600 UTC (Fig. 7d). The largest diurnal range $\left(0.8 \mathrm{~g} \mathrm{~kg}^{-1}\right)$ in the observed moisture occurs at around $900 \mathrm{hPa}$ (Fig. 7c). While the vertical structure of the simulated tempera- 

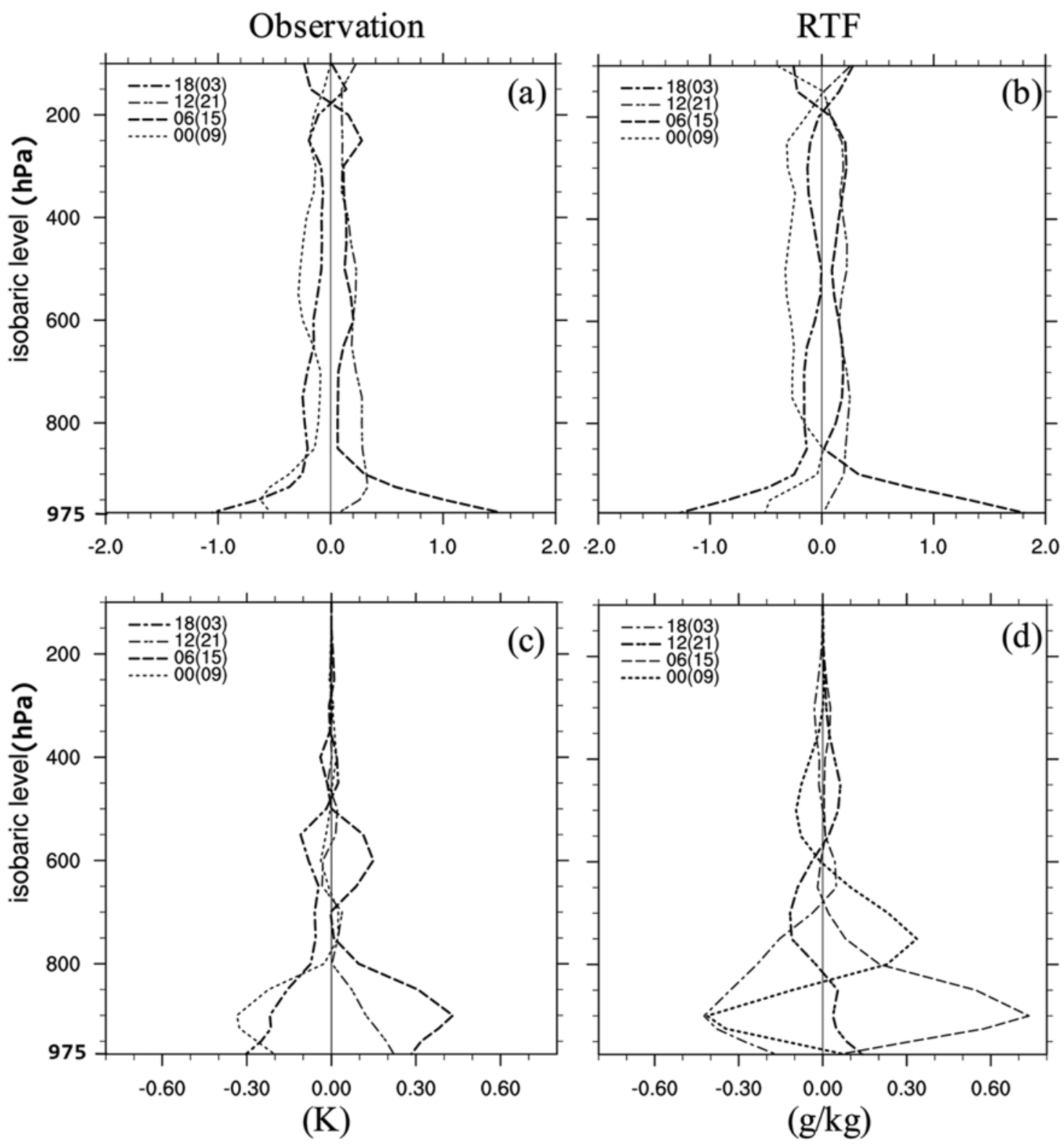

Fig. 7. (a, b) Daily anomalise of the vertical structure for temperature $\left({ }^{\circ} \mathrm{C}\right)$ and $(\mathrm{c}, \mathrm{d})$ mixing ratio $\left(\mathrm{g} \mathrm{kg}^{-1}\right)$. Due to the difference in time interval, the RTF results have 4 more solid lines: 0000 UTC (dotted line), 0600 UTC (dashed line), 1200 UTC (dash-double dotted line), and 1800 UTC (dashdotted line).

ture in the diurnal range is similar to the observed one, the structure of the simulated moisture at lower levels shows much difference from the observed one. The RTF model exhibits anomalies with almost double the value at 0600 UTC. The vertical structures of the daily moisture and temperature anomalies in RTF show that the diurnal variability is confined to the lower levels.

Bechtold et al. (2004) showed that simulated diurnal variation of tropical precipitation is very sensitive to the cumulus parameterization in land areas. The sensitivity of cumulus parameterization schemes (CPS); The Kain-Fritsch, Betts-Miller-Janjic (BMJ) and Grell-Devenyi ensemble (GD) cumulus parameterization schemes are compared to see differences in the diurnal variation of simulated precipitation during Period_2. Figure 8 shows the result of the CPS experiment. BMJ and GD schemes reduce the over-estimated precipitation amount at the maximum peak of the KF scheme. The BMJ scheme shows reasonable amount of simulated precipitation and its diurnal variation in this study.

To understand the possible reasons for the differences in the maximum precipitation simulated by the model with different CPS, area-averaged vertical bias from observation profiles of temperature, moisture, and moist static energy are examined over the South Korea region at 06 UTC (Fig. 9). The KainFritsch (KF) scheme simulates considerably large amount of moisture below $850 \mathrm{hPa}$ (Fig. 9a). The KF scheme also simu- 


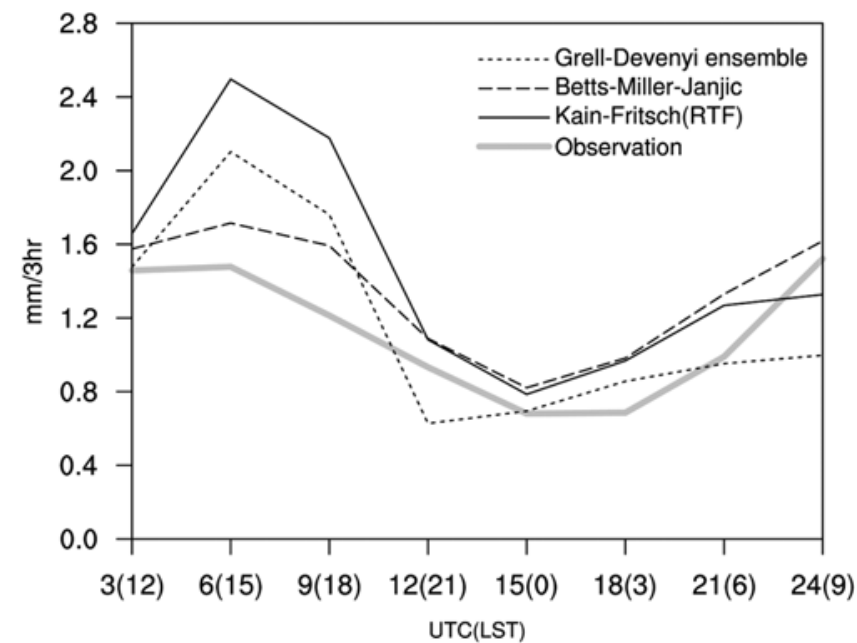

Fig. 8. Diurnal variation of precipitation during Period_2 for the CPS experiment. Thick solid line represents observation, and thin lines indicate Kain-Fritcsh (solid), Betts-Miller-Janjic (dashed), and GrellDevenyi ensemble (dotted).

lates warm bias through the almost entire levels (Fig. 9b). The $\mathrm{KF}$ scheme produces more precipitation to reduce instability resulted from excessive moisture below $850 \mathrm{hPa}$, and in consequence produces more latent heat in the mid troposphere. In the KF scheme, the simulated moisture amount below $850 \mathrm{hPa}$ would be one of the considerable factors to simulate excessive precipitation at the daytime. The moist static energy well shows the results (Fig. 9c)

\section{Summary and Conclusion}

The purpose of this study is to examine the diurnal variation of precipitation in the RTF system data using the WRF model over South Korea during the summer (JJA) of 2007. The spectral analysis of the observed precipitation reveals that a 24$\mathrm{h}$ cycle of precipitation is dominant. The period of the summer precipitation is divided by the end of the changma; Period_1 is influenced by large-scale disturbances, while Period 2 is affected by a local convective activity induced by thermal instability. The diurnal variation of precipitation for each period shows different phases. In Period_1, the maximum precipitation occurred at night, while in Period 2 it is dominant during the daytime. These results indicate that the diurnal variation of precipitation is dependent on the characteristics of the summer precipitation over South Korea.

While the daily variation of area-averaged precipitation in model forecast agrees well with that of the observations, the spatial distribution of time-averaged precipitation needs to be improved. In the simulation of diurnal variation, the phase is fairly consistent with the observed precipitation for both Period_1 and Period_2. However, in Period_2, the daytime rainfall amount of the simulated precipitation is overestimated and the simulated total precipitation is largely convective rain.

The overestimated precipitation during the daytime in Period 2 is associated with overestimated low-level atmosphere conditions including temperature and moisture. Daily anomalies for the simulated data showed that temperature is having a large amplitude in the lowest levels, and moisture is having a large amplitude around the $925-\mathrm{hPa}$ level. However, the diurnal ranges of both simulated temperature and moisture are larger than that observed. Therefore, a warm and moist environment in daytime is likely to intensify daytime precipitation. In the cumulus parameterization scheme sensitivity test during Period_2, BMJ scheme shows reduced amount of simulated precipitation and reasonable diurnal variation in this study. Since BMJ simulated less moisture below $850 \mathrm{hPa}$, it might give less latent heat in the mid troposphere.

This study is based on only one summer case, and therefore, a further study that includes more climatologically meaningful observational features and model forecasts experiments is required. Also, the diurnal variation which is dependent on the forecast lead time should be considered.

Acknowledgements. We thank the Mesoscale and Microscale Meteorology (MMM) division at the National Center for Atmo-

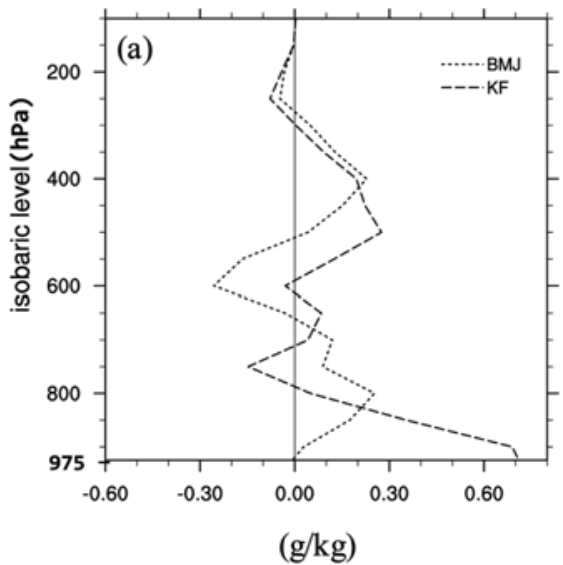

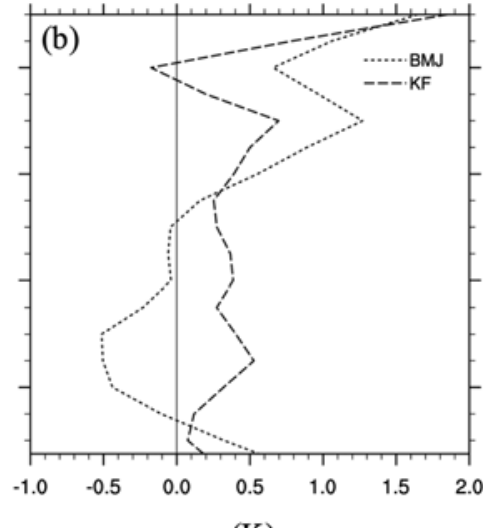

(K)

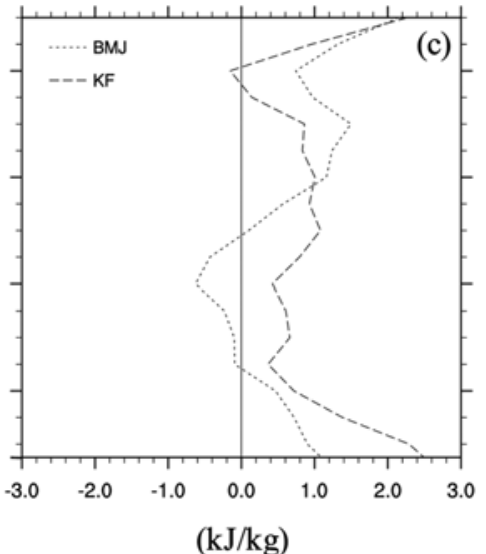

$(\mathrm{kJ} / \mathrm{kg})$

Fig. 9. Model vertical bias of (a) moisture, (b) temperature, and (c) moist static energy at 0600 UTC. Dashed lines indicate Kain-Fritcsh, and dotted lines represent Betts-Miller-Janjic. 
spheric Research (NCAR) for providing the WRF model. This study is supported by the Global Partnership Program of KICOS. The authors are grateful to the Korea Institute of Science and Technology for supporting us by providing computing resources (K20602000007-07E0200-00710). This work was funded by the Korea Meteorological Administration Research and Development Program under Grant RACS 2010-2016. We appreciate two anonymous reviewers and the editor for their valuable comments and suggestions.

\section{REFERENCES}

Basu, B. K., 2007: Diurnal variation in precipitation over India during the summer monsoon season: Observed and model predicted. Mon. Wea. Rev., 135, 2155-2167.

Bechtold P., J.-P. Chaboureau, A. Beljaars, A. K. Betts, M. Köhler, M. Miller, and J.-L. Redelsperger, 2004: The simulation of the diurnal cycle of convective precipitation over land in a global model. Quart. J. Roy. Meteor. Soc., 130, 3119-3137.

Bleeker, W., and M. J. Andre, 1951: On the diurnal variation of precipitation, particularly over central U.S.A., and its relation to large scale orographic circulation systems. Quart. J. Roy. Meteor. Soc., 77, 260-271.

Dai, A., and K. E. Trenberth, 2004: The diurnal cycle and its depiction in the Community Climate System Model. J. Climate, 17, 930-951.

Davis, C. A., K. W. Manning, R. E. Carbone, S. B. Trier, and J. D. Tuttle, 2003: Coherence of warm season continental rainfall in numerical weather prediction models. Mon. Wea. Rev., 131, 2667-2679.

Fritsch, J. M., and Coauthors, 1998: Quantitative precipitation forecasting: Report of the eighth prospectus development team, U.S. Weather Research Program. Bull. Amer. Meteor. Soc., 79, 285-299.

Grell, G. A., and D. Dévényi, 2002: A generalized approach to parameterizing convection combining ensemble and data assimilation techniques. Geophys. Res. Lett., 29, 1693, doi:10.1029/2002GL015311.

Janjic, Z. I., 1994: The step-mountain eta coordinate model: Further developments of the convection, viscous sublayer and turbulence closure schemes. Mon. Wea. Rev., 122, 927-945.

2000: Comments on "Development and evaluation of a convection scheme for use in climate models. J. Atmos. Sci., 57, 3686.

Janowiak, J. E., V. J. Dagostaro, V. E. Kousky, and R. J. Joyce, 2007: An examination of precipitation in observations and model forecasts during NAME with emphasis on the diurnal cycle. J. Climate, 20, 1680-1692.

Jung, J.-H., and M.-S. Suh, 2005: Characteristics and types of the diurnal variation of hourly precipitation during rainy season over South Korea. J. Korean Meteor. Soc., 41, 533-546. (in Korean with English abstract)

Kain, J. S., 2004: The Kain-Fritsch convective parameterization: An update. J. Appl. Meteorol., 43, 170-181.

Lim, G.-H., and H.-J. Kwon, 1998: Diurnal variation of precipitation over South Korea and its implication. J. Korean Meteor. Soc., 34, 222-237. (in Korean with English abstract)

Liu, C., and E. J. Zipser, 2008, Diurnal cycles of precipitation, clouds, and lightning in the tropics from 9 years of TRMM observations. Geophys. Res. Lett., 35, L04819, doi:10.1029/2007GL032437.

Oki, T., and K. Musiake, 1994: Seasonal change of the diurnal cycle of precipitation over Japan and Malaysia. J. Appl. Meteor, 33, 1445-1463.

Olson, D. A., N. W. Junker, and B. Korty, 1995: Evaluation of 33 years of quantitative precipitation forecasting at the NMC. Wea. Forecasting, 10, 498-511.

Skamarock, W. C., J. B. Klemp, J. Dudhia, D. O. Gill, D. M. Barker, W. Wang, and J. G. Powers, 2005: A description of the Advanced Research WRF Version 2. NCAR Tech Notes-468+STR.

Sorooshian, S., X. Gao, K. Hsu, R. A. Maddox, Y. Hong, H. V. Gupta, and B. Imam, 2002: Diurnal variability of tropical rainfall retrieved from combined GOES and TRMM satellite information. J. Climate, 15, 9831001.

Wallace, J. M., 1975: Diurnal variation of precipitation and thunderstorm frequency over the conterminous United States. Mon. Wea. Rev., 103, 406-419.

Yang, G.-Y., and J. M. Slingo, 2001: The diurnal cycle in the Tropics. Mon. Wea. Rev., 129, 784-801.

Yang, S., and E. A. Smith, 2006: Mechanisms for diurnal variability of global tropical rainfall observed from TRMM. J. Climate, 19, 5190-5226.

Zhou, T., R. Yu, H. Chen, A. Dai, and Y. Pan, 2008: Summer precipitation frequency, intensity, and diurnal cycle over China: A comparison of satellite data with rain gauge observations. J. Climate, 21, 3997-4010. 